\title{
OBSERVACIONES SOBRE EL LENGUAJE DE LA ADMINISTRACIÓN PÚBLICA*
}

\author{
Gregorio Salvador \\ Real Academia Española
}

En estas ponencias que cubren las sesiones plenarias de nuestros simposios anuales, se supone que debe partir uno del estado de la cuestión y exponer, a renglón seguido, su particular punto de vista acerca del tema.

El estado de la cuestión se despacha pronto en lo que al lenguaje de la administración pública se refiere. No ha sido entre nosotros el tal lenguaje, hasta fecha muy reciente, ocupación de lingüistas. Ni falta que hacía. Como secuela que es del lenguaje jurídico, sus peculiaridades han podido ser asunto de jurisperitos, sus ambigüedades tarea para abogados, sus formulaciones un rico filón para la imitación paródica y el chascarrillo. Al ciudadano le bastaban unas cuantas fórmulas establecidas para dirigirse a la Administración y para interpretar sus modelos de respuesta; esto constituía aprendizaje escolar, materia de enseñanza primaria. Pero he aquí que en las ig-

* El presente texto corresponde a la ponencia de clausura del XVIII Simposio de la Sociedad Española de Lingüistica, celebrado en Murcia, y se leyó la mañana del 17 de diciembre de 1987, en el salón de actos de la Caja de Ahorros de aquella ciudad. La Asociación «Antonio de Nebrija» de profesores de lengua española de las Islas Canarias me pidió que diera una lección, con este mismo tema, para clausurar un curso que había celebrado la primera semana de febrero de 1988. Se dictó en la Universidad de La Laguna el día 6 de ese mes. Con leves modificaciones, sirvió también para una conferencia que, organizada por la Universidad de Granada, pronuncié en Almería el 27 de abril de 1989. En ambas ocasiones, la de La Laguna y la de Almería, se repitió a instancias de personas que habian escuchado la ponencia de Murcia, y no son pocas las que, desde entonces, me han apremiado a su publicación. Agradezco, pues, la hospitalidad que me brinda la revista EPOS, aceptando el texto tal cual, pues yo soy totalmente reacio a transformar, forzadamente, en articulo de revista lo que ha sido texto hablado y concebido como tal. 
notas cocinas ministeriales donde se guisan los planes de estudios se preparó, en 1978, el absurdo pastel de un programa de COU para lengua española que, con ligeras modificaciones, aún sigue vigente. $Y$ en ese programa se le concede un tema, el noveno, a «El lenguaje jurídico y administrativo». Un tema lo mismo que al español de América, por ejemplo, o a la situación lingüística de España o al uso literario del lenguaje. Convertir, pues, por imposición gubernamental, «el lenguaje jurídico y administrativo» en un tema de la misma entidad que esos otros, ha obligado a los autores de libros de texto a rebuscar en los índices y a exprimirse el magín para llenar, al menos, una lección de sus manuales.

He repasado una buena porción de ellos y he encontrado de todo. Los hay que se enredan en las diferencias diastráticas, en los tecnolectos y en otras lindezas por el estilo. Otros analizan, con prolija minuciosidad, los rasgos lingüísticos (morfológicos, sintácticos, léxicos) de textos juridicos y administrativos seleccionados al efecto. Algunos se atienen a lo que sobre el lenguaje jurídico se ha escrito por los tratadistas del derecho y, para las peculiaridades del de la administración pública, se valen de bibliografia norteamericana o inglesa, porque al parecer en todas partes cuecen habas; lo malo es que las habas anglosajonas no siempre son de la misma especie y, por ejemplo, la distinción léxica de polisílabos y monosílabos no quiere decir lo mismo en inglés que en español. Y abundan los que, con buen sentido, aprovechan la ocasión para transmitir una serie de conocimientos útiles al alumno, para enseñarle a distinguir un decreto de una orden ministerial, una sentencia de un dictamen, un anuncio de una circular y una notificación de un edicto, al tiempo que le muestran cómo se redacta un oficio o cómo se hace una instancia. Casi todos parten del principio de que el lenguaje administrativo debe buscar la precisión y huir de la ambigüedad, para acabar reconociendo que rara vez consigue esos propósitos. $Y$ todos, sin excepción, se refieren a su conservadurismo, a la fosilización de fórmulas fraseológicas y léxicas de evidente arcaismo, a la abundancia de latinismos, a sus peculiares construcciones y enrevesada sintaxis, al empleo del futuro de subjuntivo y a la proliferación de gerundios. Lo que resulta diferente, de unos manuales a otros, es la valoración de estos hechos: hay los que se rasgan las vestiduras ante tales antiguallas y dislates y los que estiman, por el contrario, que esas convenciones y fórmulas facilitan la comunicación entre la Administración y los administrados, en uno u otro sentido.

En 1980, en la Biblioteca Románica Hispánica de la Editorial Gredos, se publicó la primera monografia - hasta donde alcanzan mis conocimientos- que en España se le haya dedicado a este tema, la Introducción al estudio del lenguaje administrativo. Gramática y textos de Luciana Calvo Ramos. Se trata de una tesis doctoral bien hecha, en la que se analiza un corpus de mil ochocientas diez páginas, las que constituían el tomo que forman los números del Boletín Oficial del Estado correspondientes al mes de enero de 1974. Es una gramática del Boletín, apoyada en sus textos como 
del propio subtítulo de la obra se deduce. Señala determinadas constantes en la formación de palabras, en la procedencia del léxico, en la morfología y en la sintaxis, con una demorada atención al estilo. No se distingue suficientemente, en mi opinión, lo que es relevante de lo que no lo es; es achaque éste, por lo demás, común a estos trabajos doctorales, en los que se quiere aprovechar todo lo que se ha obtenido en el análisis y cuesta desechar lo que para el autor ha representado un notable esfuerzo, independientemente de su pertinencia. Como el libro de la doctora Calvo Ramos se ha convertido en fuente obligada de manualistas, no todos ellos seleccionan bien y algunos de esos rasgos irrelevantes se les han colado en la caracterización. En cualquier caso, la obra es muy útil y, por el momento, la única monografia disponible sobre el lenguaje de la administración pública española. Menos garantía ofrecen algunos artículos posteriores de la autora, en los que ha pasado de la descripción, siempre aprovechable, a especulaciones de escaso fuste.

Si yo entro ahora en el tema, se debe a una circunstancia muy concreta. El Centro de Estudios y Documentación del INAP, es decir, el Instituto Nacional de Administración Pública, organizó la primavera pasada un seminario sobre "Administración y Lenguaje», que se desarrolló en nueve sesiones, de cuatro horas cada una, con ponencia introductoria y coloquio posterior. Participaron en él alrededor de unas veinte personas: directores generales, secretarios técnicos de diversos Ministerios, catedráticos de Derecho Administrativo, letrados de las Cortes, un profesor de Teoría de la Información, la mencionada doctora Calvo Ramos y yo mismo, en representación de la Real Academia Española. Se me encomendó la penúltima de las ponencias, sobre «La protección del castellano y el lenguaje jurídicoadministrativo", lo cual me obligó a estar muy atento a lo que alli se exponía y se discutia y a reflexionar sobre todo ello. Y fruto de tales reflexiones y contraste de pareceres son estas observaciones que traigo ante ustedes ahora. He de reconocer que aprendi mucho durante aquellas jornadas, porque, al fin y al cabo, la mayor parte de los allí presentes eran productores de textos administrativos, especialistas en su elaboración e interpretación y, además, puesto que alli estaban, personas preocupadas por la calidad lingüística de los textos que producían y, sobre todo, de los que habitualmente se producen.

Porque el lenguaje de la administración pública es un chorro que no cesa, el $B O E$ sólo nos perdona los domingos y, por si era poco, ahora hay diecisiete más, uno por cada autonomía, amén de circulares, saludas, formularios, instrucciones, notificaciones, oficios y otros textos que generan cotidianamente las oficinas públicas de modo incontenible.

Y ¿quién redacta esos textos, quién los escribe, quién es responsable de su propiedad, de su mínima adecuación a la norma lingüística? Ni se sabe. Desde luego, casi nunca quien los firma. La responsabilidad lingüística no existe. No existe porque no se exige. Siempre hay alguna desconocida me- 
canógrafa a quien atribuir el error garrafal. En la última Facultad de Filología donde he formado parte de un tribunal de tesis de Doctorado, en el acta impresa el nuevo doctor obtubo (con b) la calificación de Apto cum laude. $\mathrm{Al}$ parecer, durante muchos años - porque encargaron nada menos que quinientas - los Doctores en Filología por esa Universidad van a sufrir esa afrenta ortográfica en su expediente. $Y$ ¿a quién achacársela? ¿Quién redactó el texto del acta? ¿Quién lo mecanografió? ¿Quién lo compuso en la imprenta? ¿Quién corrigió las pruebas? ¿A quién le falta decisión para arrojar a la basura el mazo de ejemplares y encargar otros nuevos?

$Y$ si esto ocurre en una Universidad y en una Facultad de Filología, ¿qué no ocurrirá en otras dependencias administrativas? Pero dejemos, por el momento, estas minucias de impresos con faltas de ortografia, de oficios mal puntuados, de formularios ambiguos y elevémonos hasta los textos de más alto rango, los de las leyes que debemos acatar. ¿Quién las escribe? ¿A quién responsabilizar lingüísticamente de esos textos? Pues bien, hay docenas de redactores. Se acumulan esquemas, anteproyectos, proyectos; se hacen enmiendas, correcciones, supresiones. Miles de personas las ven durante su gestación y centenares de ellas intervienen, de algún modo, en su estado definitivo. Su lenguaje debiera ser sencillo, preciso, inequívoco; acaba siendo rebuscado, nebuloso y ambiguo. Pero no nos engañemos: tal vez es eso lo que se pretende. Si el artículo n. ${ }^{\circ} 811$ del Código Civil, el que trata de "El ascendiente que heredare de su descendiente» y del que se dice que admite veintisiete lecturas diferentes, tuviera sólo una interpretación, iqué iban a hacer los abogados expertos en testamentarías?

Ahí tenemos nuestra Constitución, que en este mes cumple sus nueve años, lo que es casi un milagro entre nosotros. Pero ahí está también el Tribunal Constitucional que no da abasto a resolver las dudas y recursos que originan los constantes equívocos del texto. Eugenio de Bustos ha estudiado el lenguaje de esta ley matriz y cómo se generaron algunas de sus numerosas anfibologías. En cualquier caso, las leyes fundamentales son habitualmente el fruto de componendas políticas que acaban en desdichadas chapuzas lingüísticas, y eso no parece tener remedio. Pero a esos niveles existe, al menos, la corrección de estilo y eso garantiza, si no la claridad del contenido, si una cierta pulcritud externa.

Conforme se baja en la escala jerárquica de las disposiciones, se va perdiendo en corrección y tampoco suele ganarse en propiedad. Muchas veces la elaboración del texto consiste en plagiar parcialmente otro anterior, introduciendo las modificaciones o actualizaciones que requiera la circunstancia dentro del fárrago pretérito de lo copiado. El plagio puede llegar a ser total, con grave escándalo si se descubre, como ocurrió no hace mucho con la orden ministerial que regulaba la disciplina académica, calcada del reglamento que había promulgado, al efecto, Ruiz Jiménez en sus tiempos de Ministro de Educación Nacional. Aquí las especiales circunstancias del caso lo sacaron a la luz pública, pero el procedimiento es muy frecuente y, 
en el maremagno legislativo, nadie advierte que tal disposición del Ministerio de Agricultura sobre la recolección de la aceituna lo que hace es repetir ce por be una orden de 1964, por ejemplo, que a su vez copiaba una resolución de 1952. Y peor es cuando se varía algo, porque entonces surgen las contradicciones dentro del mismo texto, que ordena, a lo mejor, en su artículo once lo contrario de lo establecido por el artículo siete. Y, en lo que a nosotros nos afecta, lo malo es cuando se quiere enmascarar el plagio con variaciones de redacción que, intercaladas aquí y allá, suelen hacer el tex to absolutamente ininteligible.

La repetición como norma, el plagio como método, podriamos decir que constituyen el fundamento del discurso administrativo. Nuestras Universidades son autónomas ahora, como es bien sabido. Ellas convocan sus propios concursos para cubrir plazas de profesorado. Cualquier B.O.E. podría servir, pero les invito a ustedes a que consulten, por ejemplo, el n. 139 de este año, el del 11 de junio pasado, entre las págs. 17604 y 17618: la Universidad de Cádiz, la del País Vasco y la Autónoma de Madrid convocan, sucesivamente, en esas páginas determinadas plazas vacantes. Pues bien, las tres resoluciones no puedo decir que sean idénticas, porque sería notoria y comprobable inexactitud. Mientras Cádiz comienza «De conformidad con lo dispuesto en la LRU, etc.», las otras prefieren «De acuerdo con lo dispuesto...». Mientras el articulado de Cádiz se va encabezando con Uno, Dos, Tres, escritos con todas sus letras, la Autónoma opta por los guarismos correspondientes y el País Vasco por los ordinales Primero, Segundo, Tercero. Cambian también los precios: En el País Vasco cobran 480 pts. por formación de expediente, tal vez por el exceso gráfico que ocasiona el bilingüismo, mientras las otras dos Universidades se conforman con 400 . Un cotejo minucioso de las tres resoluciones tal vez les permitiría encontrar alguna otra discrepancia. Lo único claro, en términos generales, es que, de las quince páginas consideradas, cinco repiten a otras cinco que son, a su vez, copia de las cinco anteriores. Y quizá pudiera hablarse otra vez de precios, porque resulta que el Boletin sí que lo pagamos todos.

Estas y otras cosas por el estilo se mencionaron en el referido seminario. Porque, si se organizó, fue con espíritu autocrítico, con ánimo de señalar defectos y de hallar soluciones que puedan poner remedio a los dislates. Hay conciencia en la Administración pública, o cuando menos en muchos de sus representantes, de que su lenguaje puede mejorar, de la inanidad de la mayor parte de sus textos. Y, aparte coloquios, seminarios y centros de estudio, algún remedio se ha arbitrado, acaso con mejor buena voluntad que acierto, desde los propios centros de poder. Me refiero a la conocida, entre los funcionarios, como "Orden de San Fermín», porque la dictó el Ministro Moscoso el 7 de julio de 1986, orden ministerial encaminada, dice, «a eliminar trabas burocráticas entorpecedoras y requisitos formales innecesarios que dificultan el establecimiento de un clima adecuado en las relaciones entre la Administración y los ciudadanos» porque «los documentos 
que materializan las relaciones Administración-ciudadano, incluso los que se ajustan a modelo oficial, contribuyen frecuentemente de modo negativo al acercamiento entre ambos, bien sea por la oscuridad del lenguaje, etc.»

Yo quisiera tener aquí la chispa de aquellos colaboradores de $\mathrm{LaCO}$ dorniz, que desde sus famosas secciones del «Papelín general» y de «La cárcel de papel», hicieron más con sus rechiflas semanales por la contención y equilibrio del lenguaje administrativo de lo que pueda conseguirse por la vía de las mesas redondas y las jornadas de estudio.

Con La Codorniz en los quioscos tal vez Moscoso se lo hubiera pensado dos veces. Porque ese idilio que propugna entre la Administración y los administrados lo considera dificultado por el hecho de «que la forma esencial de los documentos se confunde a veces con el mantenimiento de formulismos sin significado ni valor alguno", impedimento que generosamente elimina en el punto dos del artículo $2 .^{\circ}$, donde dispone que «No se consignarán en las comunicaciones administrativas, o en los modelos de documentos que hayan de dirigirse a la Administración fórmulas de salutación o despedida, ni expresiones o giros que no sean esenciales para la exposición del contenido del documento». O sea que para facilitar las relaciones entre la Administración y los ciudadanos lo que hay es que prescindir de ceremonias, entrar en el asunto a la pata la llana y despedirse luego a la francesa. Me hubiera gustado ver la cara del ministro y escuchar sus nerviosos timbrazos, si se le llega a colar en el despacho un administrado espetándole sin más preámbulo: «A ver cuándo me pagan la jubilación, que llevo siete meses sin ver una perra».

La mentada Orden de San Fermín fue recibida sin humor, pero sí alborozadamente, por algunos periódicos: "Ya no habrá que poner lo de Dios guarde en las instancias», leí yo en un titular aquel verano, y en otro, más contundente, "Se suprime el Dios guarde en todos los escritos oficiales». Por eso una alumna de mi Facultad, que tuvo que dirigirme una instancia dos meses más tarde, ya en septiembre, como Director que yo era entonces del Departamento, tras mucho Ilmo. Sr. y mucho expone y mucho suplica, concluía de este sorprendente modo: "Muchos besos de Estrella.»

Lo del suplica es otra; se olvida que es una fórmula convencionalmente aceptada, porque la súplica en Derecho se define como «la cláusula final de un escrito dirigido a la autoridad administrativa o judicial en solicitud de una resolución". Pues bien, hay quien se ve a si mismo sumiso, esclavizado y hasta arrastrándose por los suelos si escribe la palabra, y los impresos oficiales la van sustituyendo por solicita, lo cual no es demasiado grave, si bien se mira, porque como ambas palabras se parecen, en la ojeada superficial que se les dedica ni se advierte la diferencia, y los necios quedan así satisfechos y no se sienten disminuidos. Lo malo es que, admitida la sustitución del suplica, éste puede tirar del expone, que se convierte a veces en manifiesta o declara, y esta cuestión de las fórmulas consagradas no es, en el lenguaje administrativo, asunto baladí, porque son palabras que actúan 
como signos demarcativos, que ordenan el texto, que distribuyen los contenidos y que son esenciales para una lectura rápida y eficaz. Si se modifican, si se alteran, si se suprimen, el texto pierde sus contornos, su prevista organización, y se convierte en prosa apelmazada, en magma elocutivo, lo que, quiérase o no, dificulta el trabajo del funcionario y suele ser fatal para las pretensiones del solicitante.

La Orden de San Fermín anda muy descaminada en eso de los «formulismos sin significado ni valor alguno». Significado, en sentido estricto, no tienen, puesto que han devenido en palabras vacías, pero valor sí, y mucho. Prescindir de ellos es como intentar hacer un soneto en verso libre y con las estrofas a capricho. Podrá decirse algo en el texto, pero ya no será soneto y la clave de su interpretación será muy otra. Por lo demás, aunque se afirma la carencia de significado de las fórmulas, su comportamiento ante ellas es como si efectivamente lo tuvieran, como si fueran otra cosa que fórmulas, como si fueran palabras llenas. De no ser así, resultaria inexplicable la manía contra el Dios guarde y el suplica. De la primera se dice que es un arcaísmo fosilizado en el estilo administrativo y que la modernización de ese estilo exige su eliminación. Pero de arcaísmo nada. En mi tierra, que es esta misma del sudeste español en que ahora estamos, "Dios guarde» sigue siendo la forma popular de saludo en los medios rurales. Hace veinte años yo escribí un artículo gramatical, absolutamente serio y copiosamente documentado, que se titulaba "Cuando dios es un morfema». No me lo quisieron publicar, porque yo no quise cambiarle el título, que era lo que se me pedía. Aunque escribía dios con minúscula y subrayado, «como Dios manda". Pues bien, en los últimos años, salvo Santiago Carrillo, que sabe lo del morfema, hay legión de políticos a los que el dios morfológico o formulario se les diviniza en seguida, acaso como reflejo de sus anteriores tratos con él, y en cuanto han podido lo han proscrito de los oficios y de las instancias, para evitarse añejos recuerdos indeseados.

A mi toda esta gente que se toma al pie de la letra las fórmulas de cortesía me recuerda al portero del Colegio de San Bartolomé y Santiago, de Granada, que allá por mis años jóvenes de estudiante universitario, contestaba indefectiblemente al «Buenos dias, Manuel» con que lo iban saludando, cada mañana, estudiantes y profesores con un inquietante "A la noche lo veremos».

Para defender estos cambios, estas supresiones, esta supuesta modernización, se ha llegado a decir - lo oi en ese mentado seminario- que «hay que dotar de creatividad al lenguaje administrativo». En general, cada vez que escucho, en estos últimos tiempos, la palabra creatividad empiezo a sentir temblores. No quieran, pues, saber el repeluzno que me dio cuando la oi en ese contexto. ¿Imaginan ustedes un lenguaje administrativo dotado de creatividad? He aqui al jefe de negociado buscando la necesaria inspiración para redactar cada comunicación o cada oficio con la originalidad requerida. $O$ los secretarios generales de las tres Universidades que antes 
cité pretendiendo encontrar su personalísima y singular manera de comunicar a cada posible concursante que «habrá de tener cumplidos dieciocho años y no haber cumplido sesenta y cinco" o que no podrá «haber sido separado mediante expediente disciplinario del Servicio de la Administración del Estado o de la Administración Autónoma Institucional o Local ni hallarse inhabilitado para el ejercicio de funciones públicas». A lo mejor la sorprendente resurrección de la Retórica y la Poética en los nuevos planes de estudio que se preparan tiene algo que ver con el deseo de formar futuros funcionarios de la Administración pública capaces de tales virguerias elocutivas, de florear el estilo administrativo y convertir el decreto en un género literario.

Precedentes hay. En el B.O.E. del 27 de octubre de 1972, firmado por el Ministro Villar Palasí, se publicó uno en el cual se declaraban parajes pintorescos determinados lugares de la Costa Brava y se leian párrafos como el siguiente: «Es en esta parte norte donde la costa es brava de veras, ya que sus montañas caen a pico sobre el mar en acantilados fragorosos, la tierra es hosca y renegrida, el mar es animoso y contesta al reto de la tierra con una espuma rabiosa. Hay en verdad algo de ensañamiento y de ferocidad en esos cabos y peñascales que se lanzan al asalto del mar.» Claro que entonces existía aún $L a$ Codorniz que, incomprensiva ante tal derroche de creatividad legislativa, condenó al señor Ministro a siete días y una hora de prisión en su "Cárcel de Papel».

En el extremo opuesto del éxtasis lírico o del aleccionamiento moral, que siguen brotando aquí y allá, sobre todo en los preámbulos de leyes y decretos, se encuentra el estilo absolutamente esotérico, intencionadamente técnico e inclinadamente jergal. El Ministerio de Hacienda es el más reiteradamente acusado de cultivar esta prosa cerrada, para iniciados, en la que se desdeña por completo al infeliz y acuciado destinatario. Si hay alguien que entienda los folletos explicativos de cómo hay que realizar la declaración del impuesto sobre la renta, habrá que felicitarlo, pero es posible que su habilidad interpretativa tenga contados los meses, porque tal vez los próximos, que serán distintos, escapen ya a su facultad de comprensión.

Acaso la sesión más polémica del citado seminario fue la correspondiente a la ponencia del señor Sánchez Blanco, representante de la Secretaría General Técnica de ese Ministerio. Tal vez los ánimos estaban excitados porque era el 16 de junio y todo el mundo andaba a vueltas con su declaración. Nos mostró un glosario de términos fiscales recientemente publicado, pero resultaba que era más dificil entender las explicaciones del glosario que los propios términos necesitados de explicación. Reconoció con buen talante que el texto de los folletos explicativos era laberíntico y el glosario no suficientemente claro, y contó una anécdota a la par aleccionadora y espeluznante: Días atrás lo había llamado un compañero suyo, inspector de Hacienda jubilado dos años antes, porque tenía dudas para rellenar un apartado de su propio impreso de declaración: «Es que me habéis cambiado las 
palabras, eso ya no hay quien lo entienda), le dijo. El suceso me trajo a la memoria - y lo conté allí - el relato más parecido que podía recordar, el caso de aquel personaje del hampa madrileña, ladrón de oficio, que, en una novela de Zunzunegui, tras pasar un año en la cárcel, se reúne con sus compinches en una taberna de Vallecas y al rato les empieza a pedir explicaciones, porque están preparando el desvalijamiento de un piso pero han cambiado ya algunas claves de la jerga y él no se entera de la mitad de las cosas que dicen.

Quedamos aquel día en que el lenguaje de la administración pública podría ser más o menos correcto, más o menos farragoso o reiterativo, pero que lo que resulta absolutamente intolerable es que, en alguno de sus sectores, pueda convertirse en manifiesta jerigonza. Y en grado sumo si ese sector es el que más directamente afecta al bolsillo del ciudadano, ciudadano que era antes, en la terminología de la hacienda pública, un contribuyente y la jerga del I.R.T.P. lo ha transformado en sujeto paciente, yo me atrevería a afirmar que con sádico regodeo.

Tal vez a la prosa fiscal lo que haya que pedirle no es modernización sino arcaísmo. Por ejemplo, los textos medievales que se refieren a los tributos son de una claridad meridiana, para un lector actual, si los contrasta con los mandatos e instrucciones que él recibe al respecto. Yo ofrecí a la comparación todo el galimatías actual sobre exenciones por viudedad con hijos mayores o menores y la nítida contundencia del artículo décimo del Fuero de Teruel, «De biuda, cómo deue pechar», que dice asi: «Encara, toda biuda que tal fijo non oujere con el qual sostenga su casa e sus lauores, media pecha peche segunt la razon de su poder. Qual derecho es que la biuda que tal fijo oujere con el qual cumpla sus lauores e sostenga su casa en vez de su marido, toda la pecha peche segunt razon de sus uezinos.»

Otro de los ponentes fue el Secretario General del Tribunal Constitucional, que trató de poner de relieve la modernización lingüística que han representado las sentencias de este alto tribunal frente a las con frecuencia farragosas y hasta en ocasiones ininteligibles del Tribunal Supremo. Atribuyó esa modernidad al predominio de catedráticos en su composición, que son el doble que los magistrados y que propenden, dijo, más que éstos, al rigor expositivo y a la claridad didáctica. Llamó la atención especialmente sobre la ruptura con el gerundio que se advertía en la redacción de estas sentencias. Hubo discrepancias en el coloquio y yo me propuse leer cuidadosamente las sentencias que se nos habian facilitado, como ejemplo, y analizar sus posibles virtudes estilísticas.

Parece el momento de recordar que el gerundio tiene mala prensa, se considera forma vitanda y se supone que toda supresión de gerundios pule y clarifica el enunciado. Es más, una de las lacras que se le han señalado con frecuencia al lenguaje administrativo es la del uso inmoderado de gerundios, lo que no deja de ser cierto, hasta el punto de que Manuel Seco, entre las catorce clases de gerundios que detalla, incluye, con el número 
nueve, el que llama gerundio del "Boletín Oficial», el de "Orden disponiendo" o "Decreto estableciendo". Pero no todos los gerundios son sustituibles ni algunos aparentes gerundios lo son. Me refiero a los famosos resultandos y considerandos juridicos, que como su propia flexión plural indica no son tales gerundios, sino sustantivos. Pues bien, la gran clarificación aportada por el Tribunal Constitucional consiste en llamarle a los resultandos hechos y antecedentes y a los considerandos fundamentos juridicos. Como el Diccionario define resultando, sustantivo masculino, como 'cada uno de los hechos y antecedentes enumerados en sentencias, autos judiciales o resoluciones gubernativas' y considerando, también sustantivo masculino, como 'cada uno de los fundamentos jurídicos que preceden y sirven de apoyo a un fallo o dictamen', la supuesta modernización lingüística, la alabada ruptura con el gerundio, ha consistido, amén de confundir las partes de la oración, en sustituir sustantivos específicos por perífrasis genéricas, en trocar la precisión técnica por la ambigüedad amorfa, en suponer tan ignorantes y lerdos a los ciudadanos como para tener que presentarles con fórmulas vagamente explicativas realidades argumentales que tienen nombres concretos, venerables y antiguos.

$Y$ esto me puso en la pista de lo que creo que constituye la tendencia lingüísticamente más dañina de las que caracterizan el lenguaje de la administración pública. $Y$ no es una tendencia reciente sino que viene actuando desde hace varios decenios. Es lo que se ha llamado perífrasis, al caracterizar este lenguaje, pero que es algo más que una perífrasis, supera incluso los límites de la perisología y se convierte en el circunloquio llevado hasta el absurdo. Se trata esencialmente de sustituir las palabras por sus definiciones, lo que, con términos de la moderna lexemática, podríamos describir como 'el hablar con semas, en vez de con lexemas'. Allá por los años sesenta, cuando las obligaciones de un cargo académico me exigian el ojeo cotidiano del Boletín Oficial, encontré, por azar, una perla de este tipo, que alguna vez he recordado. Se trataba de un Decreto, producido nada menos que por una Comisión interministerial de media docena de Ministerios, por medio del cual se regulaba la fabricación, la distribución y comercialización en todo el territorio nacional, la exportación, los cupos, modalidades, clases y características de los «azúcares aromatizados con asidero de madera». Tan enigmático me resultaba el producto asi denominado que me adentré en la lectura del Decreto hasta descubrir que los rimbombantes "azúcares aromatizados con asidero de madera», que al parecer exportábamos a diversos y variados países y constituian una notable fuente de divisas, no eran otra cosa que los modestísimos pirulíes de mi infancia, que por entonces se habian rebautizado chupachús, por mor de una marca de fábrica, y ahora los oigo llamar piruletas.

La relegación implacable de los viejos nombres de muy dignas profesiones, sustituidos por estas pedanterias perifrásticas de la prosa oficial, es uno de los hechos más lamentables que están ocurriendo en el español actual, 
por dos motivos fundamentales. El primero porque toda sustitución de una palabra por una locución explicativa representa un empobrecimiento de la lengua y una falta de precisión. El segundo, porque tales veleidades favorecen la diversificación léxica entre los distintos paises hispánicos y la unidad de la lengua, que se ha mantenido incólume pese a fronteras y distancias, no deja de irse erosionando con tan irreflexivas decisiones. Pero el caso es que ya tenemos a nuestros tradicionales peritos, que habian especializado para su profesión un cultismo con cuatro siglos de antigüedad, que había tenido como significado primario y extenso el de «sabio, experimentado, hábil y acertado en alguna ciencia o arten, ya los tenemos, digo, convertidos en ingenieros técnicos, ambiguo sintagma que a nadie, lingüisticamente hablando, puede convencer; o en arquitectos técnicos a los aparejadores; o en profesores de EGB a los maestros; o en ayundantes técnicos sanitarios a los practicantes, aunque éstos se hayan trocado ya, sin más, en ateeses, reducida a palabra unitaria la sigla de la definición. El último intento conocido es el de dejarnos sin carteros, transformados ya sistemáticamente, en la prosa del Boletín e incluso en la sindical, en auxiliares técnicos de clasificación y reparto. Imaginen qué puede ser el conocido título de una famosa película convertido en «El auxiliar técnico de clasificación y reparto siempre llama dos veces"r.

Acaso la exigencia más radical que debiéramos manifestar los administrados a la Administración pública, en lo que se refiere al lenguaje que utiliza para dirigirse a nosotros, es que se deje ya de una vez de circunloquios y perisologías y llame al pan pan y al vino vino. Porque estén ustedes seguros de que, si en cualquier disposición oficial hay que hablar del pan, se hablará de una «porción de masa de harina y agua fermentada con levadura y cocida en horno", y si hay que hablar del vino, se hablará de un «licor alcohólico hecho del zumo de las uvas exprimido y cocido, de modo natural, por la fermentación». Es decir, lo habitual en el lenguaje de la Administración pública es que no se utilicen las palabras del diccionario, sino las definiciones de las palabras del diccionario. De ahí que muchos decretos, órdenes y disposiciones se conviertan en verdaderos dameros malditos, donde hay que descubrir significantes a partir de los significados, que es exactamente la operación inversa a la que estamos acostumbrados a hacer para interpretar un mensaje. Por eso la impresión de verbosidad laberíntica, de irritante garruleria que produce habitualmente la prosa oficial, dejando aparte sus frecuentes incorrecciones, su caprichosa puntuación y su desnortada sintaxis.

La guinda de todos estos dislates perifrásticos la puso el Real Decreto de 10 de febrero de 1986, también firmado por el Ministro Moscoso, en el que se legisla al respecto y se proscribe todo empleo oficial de dos honradas palabras de nuestro idioma, de significado muy preciso y uso popular generalizado, lo que constituye un hecho sin precedentes, que yo sepa, en la legislación española. En el artículo primero se dispone lo siguiente: «Los 
términos subnormalidad y subnormal, contenidos en las disposiciones reglamentarias vigentes, serán sustituidos por los de minusvalía y persona con minusvalia, con especificación, cuando proceda, de la naturaleza fisica, psíquica o sensorial de dicha minusvalían. Como estamos entre lingüistas el comentario se lo pueden ir haciendo ustedes. Quizás la única atenuante que pueda aducir el señor Moscoso es que el Real Decreto se promulgó "de acuerdo con las recomendaciones del Defensor del Pueblo».

Son muchas, como ven, las observaciones que suscita el lenguaje de la Administración pública y el viento renovador que lo atraviesa. Como el tiempo ya escasea, me referiré someramente a los formularios, cuya simple supervivencia se ha llegado a discutir, aduciendo que la obligación de rellenar unas determinadas casillas, de acuerdo con una pauta establecida, puede constituir un serio menoscabo de la libertad individual. Aparte memeces de este tipo, la verdad es que los hay enigmáticos y algunos incluso cabalísticos, que más que facilitar la tarea del administrado lo que hacen es sumirlo en hondas perplejidades y obligarlo a arduas cavilaciones. $Y$ no hablo sólo de los del Fisco, que ese es un tema que ya dejamos atrás; me refiero a impresos más cotidianos, donde también parece haber penetrado el hálito renovador de la creatividad. Lo de Lugar de nacimiento parece que todos estamos en condiciones de interpretarlo y de contestarlo, pero cuando se sustituye ese epigrafe por el de Oficina de Registro Civil en que fue inscrito hay ya más de cuatro que se quedan con el bolígrafo alzado y con la mente dubitativa, y no digamos nada de la variante estilístico-gramatical Oficina de Registro Civil en que se inscribió, donde parece atribuírsele al mamoncillo que uno era a la sazón la increíble precocidad de haber resuelto por sí mismo la necesaria diligencia. Para completar esta serie, otra posibilidad que ya existía desde antiguo es la rúbrica Naturaleza. Conocí hace años a un individuo alto, fornido, sanguíneo, a quien nombraban de apodo, en su pueblo Naturaleza Robusta, porque era éste el adjetivo que había escrito en el casillero correspondiente la primera vez que se encontró en ese trance, cuando iba a entrar en quintas.

Anda por ahí, en las Jefaturas de Tráfico, una solicitud de transferencia de vehículos, con membrete del Ministerio del Interior, donde además de campear la voz inglesa leasing, así en crudo, en uno de los epígrafes, se piden debajo dos firmas, la del Transmitente y la del Adquirente, aunque, asustado tal vez el redactor de su propia creatividad casi gongorina (la primera de las dos voces ni siquiera está en el DRAE), pone debajo de cada una, entre paréntesis y en letra más pequeña, vendedor y comprador.

Todo esto que les vengo diciendo parece cosa de risa, pero es que efectivamente lo es. De risa es poco; de carcajada. Y no lo deberia ser. Por ello, en ese seminario que les digo, se hicieron algunas propuestas para evitar tanto desatino. Sobre todo una mayor exigencia del dominio de la lengua escrita para el acceso a la función pública y, para facilitar ese dominio, dedicar más tiempo a la enseñanza de la propia lengua en los niveles pri- 
mario y secundario de la educación. Que no se diluya nunca, colectivamente, la responsabilidad de este tipo de escritos. Si el Ministro, el Ministro; si su Secretario General Técnico, su Secretario General Técnico; si tal Jefe de Negociado, tal Jefe de Negociado. Por supuesto, el rechazo de toda jergalización, para lo cual debe hacerse obligatoria la publicación, como anejo de todo texto especializado, de un glosario de los tecnicismos incluidos, con explicaciones que estén al alcance de cualquier persona de cultura media. $Y$, desde luego, no confundir la modernidad del estilo con la supresión de las fórmulas.

Quiero contarles, para acabar, que aquella chica, Estrella, la de la instancia de tan cariñosa despedida, vino luego a verme para averiguar la marcha de su asunto y les puedo asegurar que no se me lanzó a los brazos. Como no tengo motivos para suponer que no me deseara larga vida, como a cualquiera se le suele desear, resulta que el «Dios guarde a V. muchos años" hubiera estado más lleno de sentido, más cerca de la verdad, que esa otra fórmula de los «muchos besos» que, lamentablemente, nunca me llegó a dar.

Y hablando de fórmulas tendré yo que encontrar una adecuada para concluir esto, para que sepan que he terminado. Se estila ahora el «muchas gracias» o el «muchas gracias por la atención que me han dispensado», que son recientes entre nosotros, calcos del inglés que han reemplazado al más abrupto y expeditivo "he dicho" que heredamos de nuestros mayores. Por una vez y teniendo en cuenta el tema tratado y el lugar donde nos hallamos, yo me voy a despedir de ustedes deseándoles que Dios los guarde. 